\title{
Untargeted metabolomic on urine samples after a-lipoic acid and/or eicosapentaenoic acid supplementation in healthy overweight/obese women
}

Ana Romo-Hualde1, Ana E. Huerta1,2, Carlos J. González-Navarro1, Omar Ramos-López,2, María J. Moreno-Aliaga ${ }^{1,2,3,4}$ and J. Alfredo Martínez $z^{1,2,3,4,5^{*}}$ (0)

\begin{abstract}
Background: Eicosapentaenoic acid (EPA) and a-lipoic acid (a-LA) have been investigated for their beneficial effects on obesity and cardiovascular risk factors. In the current research, the goal was to evaluate metabolomic changes following the dietary supplementation of these two lipids, alone or combined in healthy overweight/obese sedentary women following an energy-restricted diet. For this purpose, an untargeted metabolomics approach was conducted on urine samples using liquid chromatography coupled with time of flight mass spectrometry (HPLC-TOF-MS).

Methods: This is a short-term double blind placebo-controlled study with a parallel nutritional design that lasted 10 weeks. Participants were assigned to one of the 4 experimental groups [Control, EPA (1.3 g/d), a-LA (0.3 g/d) and EPA+Q-LA (1.3 g/d +0.3 g/d)]. All intervention groups followed an energy-restricted diet of 30\% less than total energy expenditure. Clinically relevant biochemical measurements were analyzed. Urine samples (24 h) were collected at baseline and after 10 weeks. Untargeted metabolomic analysis on urine samples was carried out, and principal component analysis (PCA) and partial least squares-discriminant analysis (PLS-DA) were performed for the pattern recognition and characteristic metabolites identification.
\end{abstract}

Results: Urine samples were scattered in the PCA scores plots in response to the supplementation with a-LA. Totally, 28 putative discriminant metabolites in positive ionization, and 6 in negative ionization were identified among groups clearly differentiated according to the a-LA administration. Remarkably is the presence of an ascorbate intermediate metabolite (one of the isomers of trihydroxy-dioxohexanoate, or dihydroxy-oxohexanedionate) in the groups supplemented with aLA. This fact might be associated with antioxidant properties of both $a-L A$ and ascorbic acid. Correlations between phenotypical parameters and putative metabolites of provided additional information on whether there is a direct or inverse relationship between them. Especially interesting are the negative correlation between ascorbate intermediate metabolite and asymmetric dimethylarginine (ADMA) and the positive one between superoxide dismutase (SOD) and aLA supplementation.

Conclusions: This metabolomic approach supports that the beneficial effects of a-LA administration on body weight reduction may be partly explained by the antioxidant properties of this organosulfur carboxylic acid mediated by isomers of trihydroxy-dioxohexanoate, or dihydroxy-oxohexanedionate.

Trial registration: Clinicaltrials.gov NCT01138774.

Keywords: a-lipoic acid, Eicosapentaenoic acid, Obesity, Overweight, Metabolomic

\footnotetext{
* Correspondence: jalfmtz@unav.es

${ }^{1}$ Centre for Nutrition Research, University of Navarra, Pamplona, Spain

${ }^{2}$ Department of Nutrition, Food Science, and Physiology, University of

Navarra, Pamplona, Spain

Full list of author information is available at the end of the article
}

(c) The Author(s). 2018 Open Access This article is distributed under the terms of the Creative Commons Attribution 4.0 International License (http://creativecommons.org/licenses/by/4.0/), which permits unrestricted use, distribution, and reproduction in any medium, provided you give appropriate credit to the original author(s) and the source, provide a link to the Creative Commons license, and indicate if changes were made. The Creative Commons Public Domain Dedication waiver (http://creativecommons.org/publicdomain/zero/1.0/) applies to the data made available in this article, unless otherwise stated. 


\section{Background}

Metabolomics is an - omics technology that focuses on analyzing the wide variety of low molecular weight metabolites occurring in biological samples (urine, blood, tissues, etc.) [1]. Targeted metabolomic is a powerful tool to quantify of known metabolites with similar chemical structures (e.g. amino acids, acylcarnitines, organic acids, etc.) [2], while untargeted metabolomic involves the use of nuclear magnetic resonance (NMR) or mass spectrometry (MS) for the simultaneous measurement of as many known and unknown metabolites as possible in a biological specimen [3]. This latter approach is generally used to compare biological samples or clinical states and to report on differences between these situations in order to assess the complete set of metabolites - metabolome [4]. Two factors that influence the metabolome have been described: the endogenous metabolome, which involves all intrinsic metabolites related to the primary and intermediary metabolism, and the exogenous metabolome, which refers to all metabolites arising from extrinsic factors such as diet (i.e., food metabolome), microbiota, physical activity, stress, or drugs [5]. Metabolomics promises to be an important instrument in interpreting the complex relationships between factors contributing to different diseases: obesity, diabetes, cancer, etc. [6]. In this context, preliminary results on metabolomic biomarkers related to the different dietary patterns could help to better understand the inter-individual differences in cardiovascular risk and nutritional responses for further applications in precision nutrition [7].

Diverse fatty acids have been widely investigated in a number of clinical trials for their beneficial effects on obesity [8] and cardiovascular risk factors [9]. Thus, $\alpha-$ lipoic acid ( $\alpha-\mathrm{LA})$ is a naturally occurring carboxylic acid with antioxidant properties, which contains sulfur and eight carbons, being a co-factor in different mitochondrial enzymes [10]. The human body can synthesize small amounts of $\alpha$-LA through lipoic acid synthase [11]. Some studies in rodents have described anti-obesity properties for $\alpha$-LA supplementation, and also beneficial effects on hepatic steatosis, which could be mediated by its ability to restore the oxidative balance by increasing antioxidant defenses $[12,13]$. It has also been shown that $\alpha$-LA down regulates lipogenic enzymes, inhibiting lipogenesis and reducing triglyceride accumulation (through the activation of AMP-activated protein kinase (AMPK) signaling pathway) in human subcutaneous adipocytes from overweight/ obese subjects [14]. Interestingly, several meta-analyses on clinical trials carried out to study the effect of $\alpha$-LA supplementation on obesity and overweight $[15,16]$ revealed that supplementation with $\alpha$-LA slightly, but significantly decreased body weight and body mass index (BMI) [15, 16]. Further research is warranted to examine the effect of different doses and the long-term benefits of LA on weight management [16].
Other fatty acid such as eicosapentaenoic acid (EPA), which is one of the principal omega-3 polyunsaturated fatty acids (n-3 PUFA) from marine origin, is associated with anti-inflammatory properties [17]. In this context, an intervention trial has shown that EPA modulates inflammationrelated genes in adipose tissue [18]; moreover, EPA promotes changes in the adipose tissue extracellular matrix remodeling genes besides an increment of chemotactic factors and macrophages associated with wound repair [19]. Different metabolomic studies have been carried out on EPA and n-3 PUFA $[9,20]$. Thus, a lipidomic study contributed to the general knowledge of EPA on the progress of metabolic syndrome (MetS), inflammation and oxidative stress [20]. A human trial showed indirect associations with lipid molecular species and clinical variables of interest in the evaluation of the MetS after a diet high in n-3 PUFA and polyphenols [9]. Therefore, the aim of the present study was to assess the effect of dietary supplementation with $\alpha$-LA and EPA, separately or in combination during a hypocaloric diet, on urinary metabolome, in order to evaluate the presence of metabolomic changes between the different groups of the intervention.

\section{Methods}

\section{Participants and study design}

The current analyses were conducted within the framework of the OBEPALIP project [21], which is a double blind randomized placebo-controlled intervention with a parallel nutritional design, where a group of 70 healthy overweight/obese sedentary females $(37.3 \pm 7.6$ years old, and $31.6 \pm 3.1 \mathrm{BMI}$ ) was chosen. All volunteers followed an energy-restricted diet of $30 \% \mathrm{E}$ adjusted with the individual's energy expenditure assessed by indirect calorimetry [21] during 10 weeks. Macronutrient distribution was recommended according to the American Heart Association (AHA) nutritional guidelines [22]. At the initial baseline visit, the experimental prescription was personally taught by a trained dietitian and all participants were instructed about maintaining the habitual physical activity style over the trial. Furthermore, in this first visit, participants were allocated to one of the four intervention groups: 1$)$ Control group $(n=19)$ : 3 placebo-I capsules (containing sunflower oil) and 3 placebo-II capsules (containing the same excipients as the LA capsules); 2) EPA group ( $n=15): 1300 \mathrm{mg} / \mathrm{d}$ of EPA distributed in 3 capsules of EPA80 (provided by Solutex ${ }^{\oplus}$, Madrid, Spain), supplying $433.3 \mathrm{mg}$ of EPA and $13.8 \mathrm{mg}$ of DHA as ethyl-ester; and 3 placebo-II capsules; 3$) \alpha$ LA group $(n=16)$ : $300 \mathrm{mg} / \mathrm{d}$ of $\alpha$-LA from 3 capsules supplying $100 \mathrm{mg}$ of $\alpha$-LA (Nature's Bounty ${ }^{\oplus}, \mathrm{NY}$, USA), and 3 placebo-I capsules; and 4) EPA $+\alpha$-LA $(n=15)$ : $1300 \mathrm{mg} / \mathrm{d}$ of EPA (distributed in 3 capsules of EPA80) and $300 \mathrm{mg} / \mathrm{d}$ of $\alpha$-LA (from 3 capsules containing $100 \mathrm{mg}$ of $\alpha$-LA), respectively $[18,23]$. 
At the baseline and at the endpoint, the women, after about 10-12 h fasting, visited the Metabolic Unit of the University of Navarra to be interviewed by the physician, the dietitian and the nurse. Anthropometric measurements were carried out according with standardized routine protocols, as detailed elsewhere [18, 23]. The inclusion and exclusion criteria have been previously described [21].

The study was approved by the Research Committee of the University of Navarra No. 007/2009 and recorded at clinicaltrials.gov as NCT01138774. All undertakers signed the informed consent before being recruited in the assay. The intervention was conducted in accordance with the latest Helsinki Declaration guidelines.

\section{Biochemical measurement in blood and urine}

Blood specimens from overnight fasted subjects were drained on weeks 0 and 10 into Serum Clot Activator tubes $\left(4 \mathrm{~mL}\right.$ Vacuette $\left.{ }^{\odot}\right)$ and into tubes with tripotassium EDTA (4 mL Vacuette ${ }^{\circ}$ ). Plasma samples were extracted from EDTA tubes after centrifugation at $1500 \mathrm{~g}$ during $15 \mathrm{~min}$ at $4{ }^{\circ} \mathrm{C}$. All samples were adequately stored at $80{ }^{\circ} \mathrm{C}$ for posterior appropriate analyses.

Serum concentrations of glucose, total cholesterol, HDL-cholesterol, triglycerides, free fatty acids (FFA) and $\beta$-hydroxybutyrate were routinely assessed by using the Pentra C200 (HORIBA medical, Madrid, Spain) autoanalyzer. The values of LDL-cholesterol were calculated using the Friedewald equation. Also, plasma concentrations of asymmetric dimethylarginine (ADMA) and insulin were measured according with the manufacturer's instructions for available commercial ELISA kits provided by DLD Diagnostika GMBH (Hamburg, Germany) and Mercodia (Uppsala, Sweden), respectively [18]. The homeostasis model assessment (HOMA-IR) was defined as fasting serum insulin $(\mathrm{mU} / \mathrm{L}) \mathrm{x}$ fasting plasma glucose $(\mathrm{mmol} / \mathrm{L}) / 22.5$ [24]. Superoxide dismutase (SOD) activity was measured with a kit according to manufacturer instructions (Assay Designs, PA, USA) as described elsewhere [21]. ADMA was assessed in the samples as marker of metabolic syndrome manifestations an oxidative status [25], and SOD was measured as biological marker of oxidative stress [26], as positively related with the $\alpha$-LA antioxidant properties.

Complete $24 \mathrm{~h}$ urine samples were picked up the day prior to the start and the day before the endpoint of the study. Urine specimens were collected in a urine container and chilled at $4{ }^{\circ} \mathrm{C}$. As designed, the urine samples were stored in vials of $1 \mathrm{~mL}$ at $-80{ }^{\circ} \mathrm{C}$ until analysis.

\section{Sample preparation and HPLC-TOF-MS analysis}

All used solvents were of liquid chromatography-mass spectrometry (LC-MS) grade and purchased from Scharlau (Scharlab, Sentmenat, Spain). Analytical water (18.
$2 \mathrm{M} \Omega$ ) was provided from an Ultramatic system from Wasserlab (Barbatáin, Navarra, Spain). Other standards were of analytical or higher grade, and were supplied by Sigma Aldrich (Sigma-Aldrich Chemie Gmbh, Steinheim, Germany).

The analytical procedures have been thoroughly described elsewhere [27]. In brief, urine samples were warmed up, centrifuged, diluted with $100 \mu \mathrm{L}$ of Milli-Q water and vigorously vortexed. The solution was finally transferred to a vial for subsequent analyses. High Performance Liquid Chromatographic (Agilent Technologies 1200, CA, USA) coupled with Mass Spectrometry (Agilent Technologies 6220 Accurate-Mass TOF LCMS, CA, USA) was available for the analysis. MS operated in positive electrospray ionization (ESI+) or negative electrospray ionization (ESI-) mode. The HPLCTOF-MS system was controlled by MassHunter Workstation 06.00 software (Agilent Technologies, Barcelona, Spain). The used column was a Zorbax SB-C18 $(15 \mathrm{~cm} \times$ $0.46 \mathrm{~cm} ; 5 \mu \mathrm{m}$ ) with a SB-C18 precolumn (Agilent Technologies, Barcelona, Spain) at $40{ }^{\circ} \mathrm{C}$. The mobile phase involved water with formic acid $0.1 \%$ (A) and acetonitrile with formic acid $0.1 \%$ (B). The gradient for elution, 1$20 \%$ B, 0-4 min, 20-95\% B 4-6 min, 95\% B 9-7.5 min, 95-1\% B 7.5-8 min, 1\% B 8-14 min. Afterwards, the column was re-equilibrated for $5 \mathrm{~min}$ at $1 \% \mathrm{~B}$. The flow rate was $0.6 \mathrm{~mL} \mathrm{~min} \mathrm{~min}^{-1}$ and the injection volume was $15 \mu \mathrm{L}$. ESI conditions were: gas temperature, $350{ }^{\circ} \mathrm{C}$; drying gas, $10 \mathrm{~L} \min ^{-1}$; nebulizer, 45 psig; capillary voltage, $3500 \mathrm{~V}$; fragmentor, $175 \mathrm{~V}$; and skimmer, $65 \mathrm{~V}$. The equipment was set out to work over the $\mathrm{m} / \mathrm{z}$ range

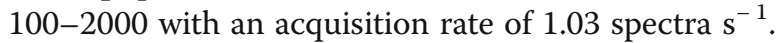

To assess the quality in this metabolomic approach, a previously reported procedure with some minor modifications was applied [28, 29]. Two kinds of sample quality control (QCs) were implemented: i) standard mixture solution implemented of cytosine, L-carnitine hydrochloride, betaine, leucine, deoxyadenosine and deoxyguanosine at a concentration of $1 \mathrm{mg} / \mathrm{L}$. ii) pooled urine was prepared by mixing equal volumes from each of the 130 samples. These samples were injected 5 times at the beginning of the run to ensure system equilibration, and then every 5 samples to further monitor stability of the analysis. Finally, samples were randomized to reduce the systematic error associated with measurements variability. Urine specimens were sequentially analyzed in sets of 15 samples/day.

\section{Data processing and metabolite identification}

LC-MS data were analyzed with the XCMS Online software (https://xcmsonline.scripps.edu) to identify and line up features [30-34]. The alignment applied a $0.2 \mathrm{~min}$ retention time and a 0.002 Da mass tolerance window. 
A pilot trial was performed to characterize metabolites by means of the METLIN (https://metlin.scripps.edu/ index.php) within a mass precision below $5 \mathrm{mDa}$, the scientific literature and the metabolic pathways described in Kyoto Encyclopaedia of Genes and Genomes (KEGG) database (http://www.genome.jp/kegg/), Human Metabolome Database (HMDB) (http://www.hmdb.ca/) and Lipidmaps (http://www.lipidmaps.org/). In those cases in which the METLIN search offered several metabolites, the use of commercial patterns allowed us to discard some of the resulting options, allowing a more accurate approximation to the putative metabolite.

\section{Statistical analysis}

Statistical analyses were carried out with the Stata Statistical Software (Release 12. College Station, StataCorp LLC, TX, USA). For all performed tests, the statistical significance (two-sided) was set at $p<0.05$. The ShapiroWilk analysis was used to check the sample normality. Anthropometric and biochemical parameters at baseline were compared between groups by a one-way analysis of variance (ANOVA) or Kruskal-Wallis tests, as statistically appropriate. Moreover, the percentage of change, defined as [(endpoint-baseline) / baseline] $\times 100$, was compared by two-way ANOVA and adjusted by the respective value at baseline when proper. Moreover when a statistically significant interaction was found (EPA $x$ LA), a contrast analysis was applied to identify which conditions were different from each other.

Metabolomic profile examination encompassed diverse multivariate data analysis procedures such as principal components analysis (PCA) and partial least squaresdiscriminant analysis (PLS-DA). Such analyses were implemented using MetaboAnalyst 3.0 software (http:// www.metaboanalyst.ca/). Before carrying out PCA and PLS-DA analyses, the peak intensity was controlled by a logarithmic transformation, and monitored by Pareto scaling. To research the more relevant metabolites in the PLS-DA model, variable importance in projection (VIP) scores were estimated. Metabolites with VIP score value greater than 4.0 were chosen for proof of identity. In addition, Spearman's correlations were performed between phenotypical parameters and putative metabolites.

\section{Results}

\section{Subjects}

The principal characteristics of participants and biochemical parameters at baseline and changes after the 10 week intervention concerning the 4 experimental arms following hypocaloric diets and $\alpha$-LA/EPA administration are reported (Table 1). The four experimental groups were apparently homogeneous at the baseline, where no statistical differences were found at the beginning of the trial in any of the assessed variables. BMI, fat mass and HOMA-IR reductions were significantly higher $(p<0.05)$ in those groups supplemented with $\alpha$-LA while it was observed a significant interaction $(\mathrm{p}<0.05)$ between treatments in the percentage of change of ADMA levels.

\section{Urinary metabolomic profile}

HPLC-TOF-MS method allowed the detection of 4.752 features in the ESI+ mode and 4.713 features in the ESI- mode (data not shown). Furthermore, a univariate statistical analysis performed to select those variables demonstrating significant differences $(p<0.05)$ among groups, found 711 features in ESI+ mode and 829 features in ESI- mode.

A PCA approach was used to transform the original variables into a small number of new orthogonal variables built from linear combinations explaining most of the measured data variance [35], allowing the clustering of samples from groups [36]. Initially, PCA was able to discriminate the $\alpha$-LA and the $\alpha$-LA + EPA groups from the control and the EPA groups in both, positive and negative ionization mode, but was not able to discriminate among the four groups at endpoint (Additional file 1: Figure S1). Therefore, the $\alpha$-LA and $\alpha$-LA + EPA groups in a lipoic group (LIP) were gathered, while on the other hand the control and EPA groups in a non lipoic group (NO LIP) were also merged. Using these new groups, PCA showed a clear discrimination, both in the positive and negative ionization mode, between the LIP group at endpoint and the other three ones (LIP group at baseline, NO LIP group at endpoint and LIP group at baseline [Fig. 1]). Thus, it seems that the discriminant metabolites among groups were related to the metabolism of $\alpha$-LA, and not influenced either by the energy restriction or, by the EPA treatment.

In order to identify the metabolites responsible for the discrimination among the metabolomic profiles, the VIP score was used to select those with the most significant contribution in a PLS-DA model. VIP scores are a weighted sum of PLS weights for each variable and measure the contribution of each predictor variable to the model. The compounds exhibiting the higher VIP score are the more influent variables. In this work, VIP score $>4$ were used as a criterion for feature selection that was met by 28 features in ESI+ mode, and 6 features in ESI-mode thus selected for further identification.

\section{Identification of putative metabolites}

Metabolites were putatively identified based on the information obtained from several databases, specifically the METLIN database was consulted (https://metlin.scripps. edu/index.php). Putative metabolites were detected when the mass difference between the theoretical $\mathrm{m} / \mathrm{z}$ and detected $\mathrm{m} / \mathrm{z}$ did not exceed $5 \mathrm{mDa}$. Some possible identity assignations were discarded by using commercial standards 


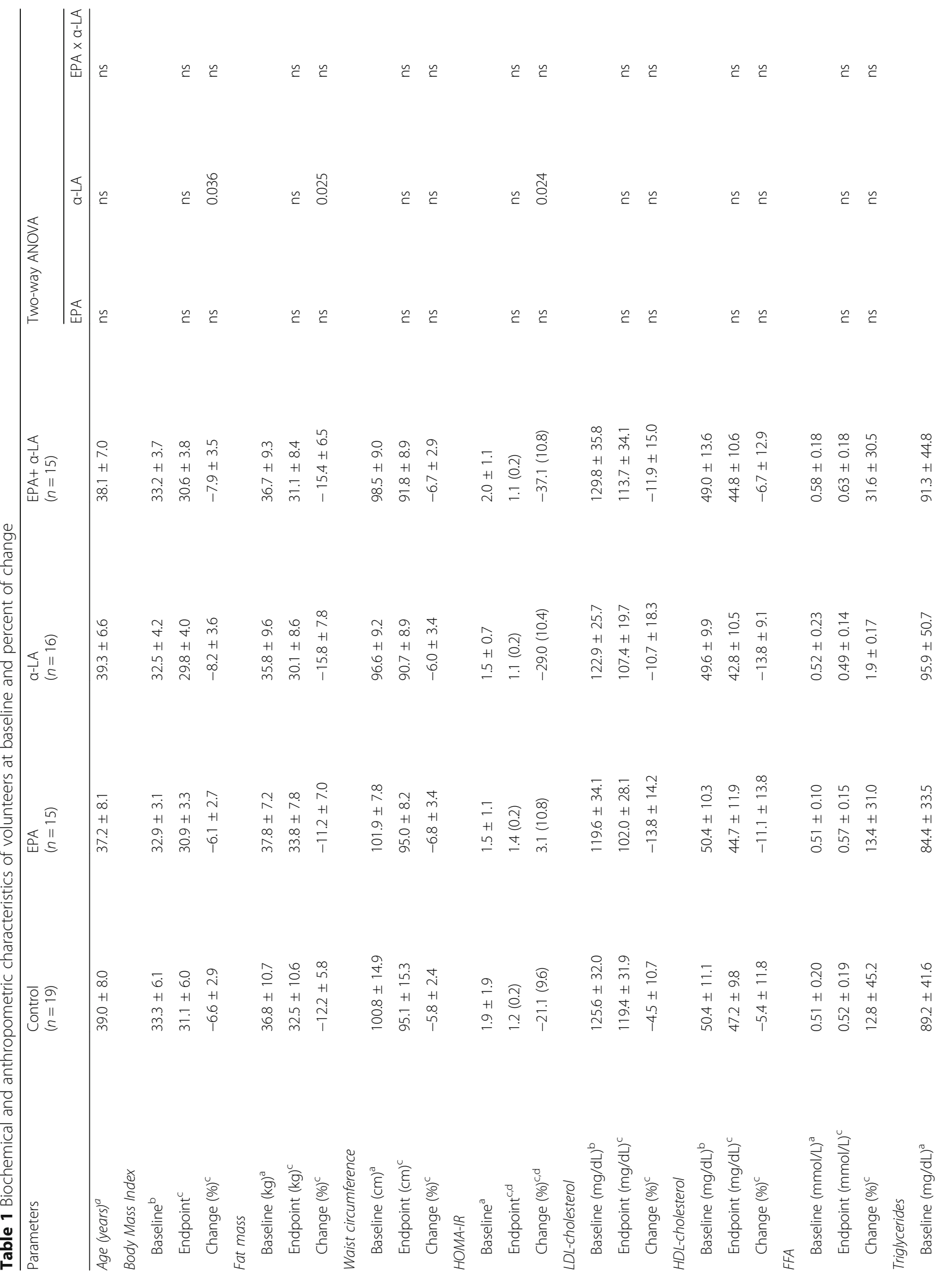




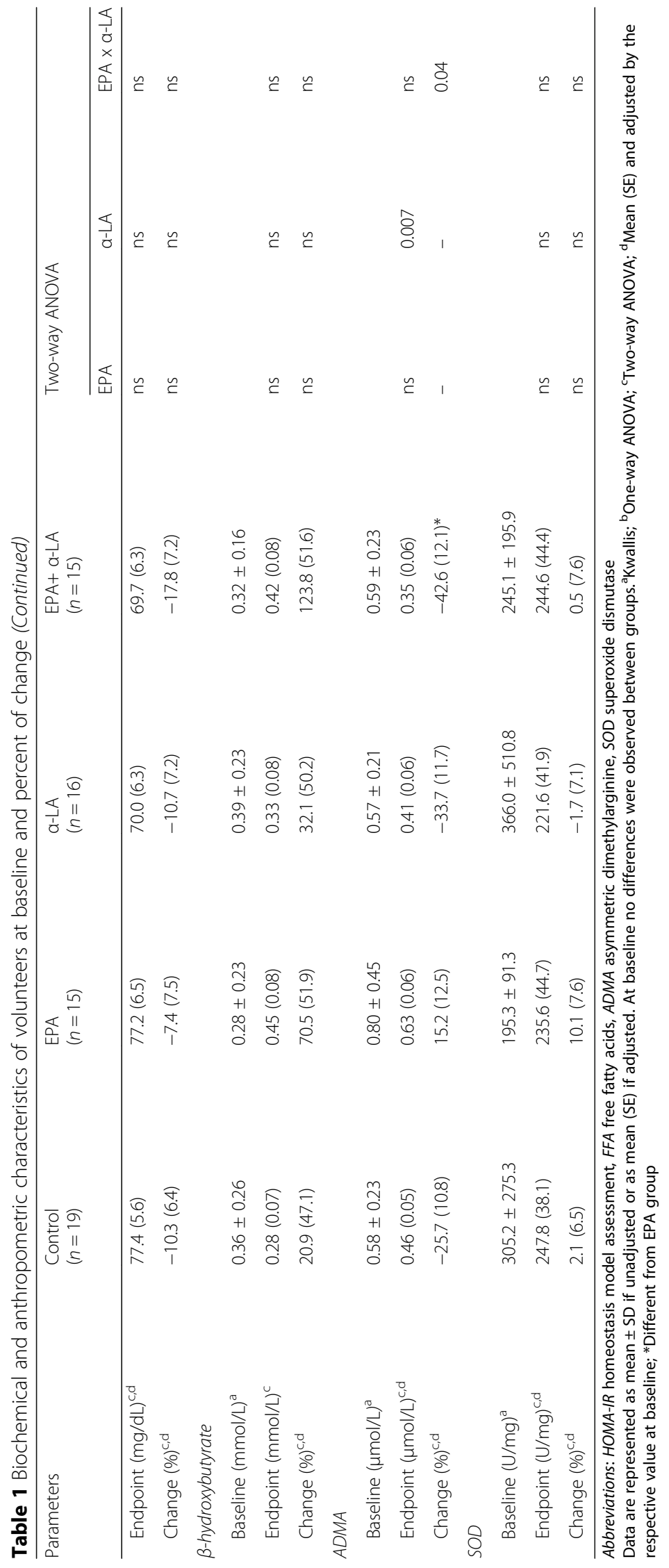




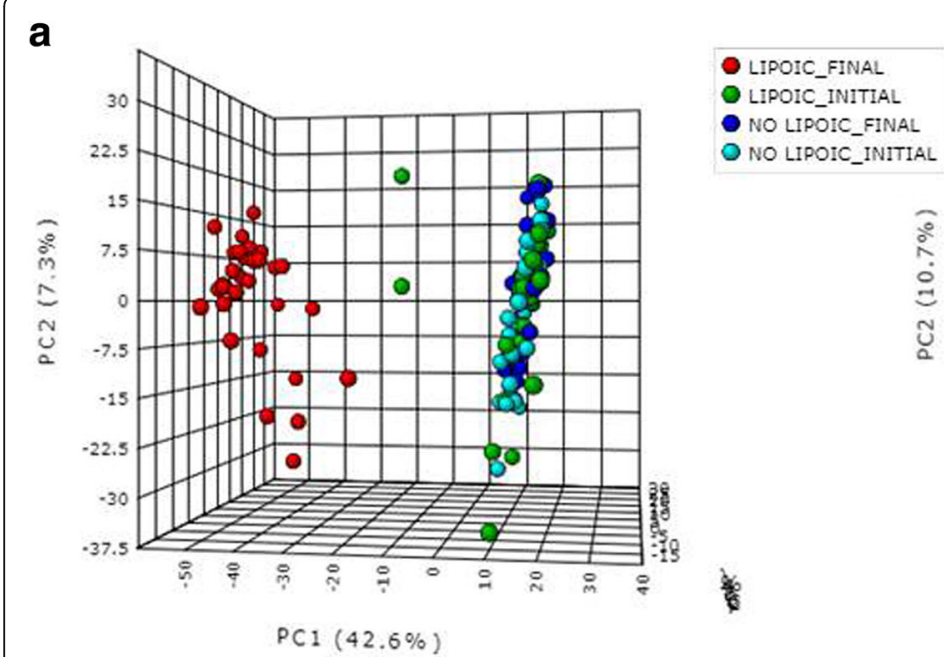

b

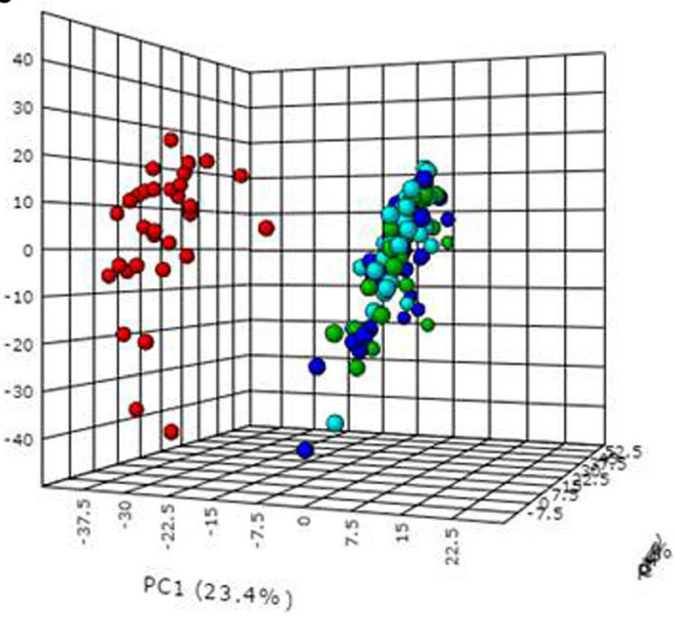

Fig. 1 Principal component analysis (PCA) of untargeted metabolomics analysis of urine samples, including LIPOIC FINAL, LIPOIC INITIAL, NO LIPOIC FINAL and NO LIPOIC INITIAL groups. a PCA in positive ionization mode (ESI+). b PCA in negative ionization mode (ESI-)

(citric acid, d-saccharic acid-1,4,-lactone). Table 2 (ESI+) and Table 3 (ESI-) contain information concerning the mean intensity of each metabolite at LIP and NO LIP baseline as well as LIP and NO LIP endpoint, retention time, detected mass, putative metabolite identification, assignation, mass difference and VIP score. Interestingly, all the putative metabolites with the highest VIP score presented an up-regulation in the LIP group at the endpoint. This fact supported the hypothesis raised above that the discriminant metabolites among the groups are associated with the intake of $\alpha$-LA. Several putative metabolites were associated with dipeptides (tryptophan proline, or prolyl cysteine), $\mathrm{CHO}$ metabolites and lipid species. One of the identified putative metabolite, isomers of trihydroxydioxohexanoate (2,3-diketo-L-gulonate; 2,5-Didehydro-Dgluconate) or dihydroxy-oxohexanedioate (5-dehydro-4deoxy-D-glucarate; 2-dehydro-3-deoxy-D-glucarate), was considered especially interesting, as it was increased at the LIP endpoint group compared to the other groups.

Correlations between phenotypical parameters and putative metabolites might offer information on whether there is a direct or inverse relationship between them (Table 4). Remarkably interesting is the negative correlation between metabolite 14 and ADMA, FFA and $\beta$-hydroxybutyrate, or the positive with SOD, which support the interplay of $\alpha$-LA administration with the oxidative status.

\section{Discussion}

The higher reductions on BMI and fat mass in those groups supplemented with $\alpha$-LA could be explained by direct or indirect effects of this organosulfur compound derived from caprylic acid on adipocyte metabolism, regulation mitochondrial biogenesis, lipid turnover (lipolysis/ lipogenesis) or inflammation $[18,23]$ as well as related to its role as antioxidant [37], and its beneficial effects on hyperlipidemia [38], or cardiovascular risk [39].

Metabolomics have been applied for pattern recognition and characteristic metabolite identification [40, 41], as well as for dietary adherence [27] metabolic fingerprinting [42], disease monitoring [43], and post-treatment outcomes [44]. Untargeted metabolomic analyses of urine samples collected at baseline and at the endpoint in a nutritional intervention might offer information on the presence of discriminant metabolites among experimental groups, since metabolomics has contributed to decipher body responses to different treatments in subjects with obesity [45], diabetes [46], fatty liver [47] and COPD [48]. Some of these discriminant metabolites, including amino acids and peptides, lipid species or food derivatives, might be established as biomarkers for subsequent studies [4951], and have been described in some situations of changes in adiposity [52] or inflammation [53]. In this context, the assessment of the effects of $\alpha$-LA (derived from a carboxylic acid with 8C) and EPA (20C) administration to obese/overweight women during weight loss [21] may beneficiate from metabolomics approaches.

Discriminant metabolites among the different groups suggest that $\alpha$-LA has an outstanding importance in the urinary metabolomic profile, independently of the effect of energy restriction. Therefore, the discriminating metabolites among the groups should be mainly related to the intake of $\alpha$-LA. Although to a lesser extent, the discriminant metabolites could be associated with the greater reduction of body weight, changes in lipid metabolism and insulin sensitivity observed in LIP groups. In any case, the involvement of the slightly, but significant higher weight loss observed in the groups supplemented with $\alpha$-LA could not be discarded [45] or the 
Table 2 Putative metabolites in ESI+

\begin{tabular}{|c|c|c|c|c|c|c|c|c|c|c|}
\hline & $\begin{array}{l}\text { NO } \\
\text { LIP } \\
\text { INI }\end{array}$ & $\begin{array}{l}\text { LIP } \\
\text { INI }\end{array}$ & $\begin{array}{l}\text { NO } \\
\text { LIP } \\
\text { FIN }\end{array}$ & $\begin{array}{l}\text { LIP } \\
\text { FIN }\end{array}$ & $\begin{array}{l}\text { VIP } \\
\text { score }\end{array}$ & $\begin{array}{l}\text { RT } \\
(\min )\end{array}$ & $\begin{array}{l}\text { Detected } \\
\text { mass } \\
(\mathrm{m} / \mathrm{z})\end{array}$ & Putative metabolites & Assignation & $\begin{array}{l}\text { Mass difference } \\
(\mathrm{mDa})\end{array}$ \\
\hline \multirow[t]{3}{*}{1} & 10.01 & 10.03 & 15.48 & 19.31 & 6.833 & 9.05 & 402.1331 & $\begin{array}{l}\text { N-Methyl-2,3,7,8-tetramethoxybenzophenanthridine- } \\
6(5 \mathrm{H}) \text {-one }\end{array}$ & {$[\mathrm{M}+\mathrm{Na}]^{+}$} & 1.90 \\
\hline & & & & & & & & Angoline & {$[\mathrm{M}+\mathrm{Na}]^{+}$} & 1.90 \\
\hline & & & & & & & & Asn-OHPhe-OH & {$[\mathrm{M}+\mathrm{H}]^{+}$} & 3.54 \\
\hline 2 & 10.76 & 12.26 & 15.28 & 20.32 & 6.785 & 6.13 & 241.0614 & Prolyl-Cysteine & {$[\mathrm{M}+\mathrm{Na}]^{+}$} & -0.30 \\
\hline \multirow[t]{2}{*}{3} & nd & nd & 13.98 & 18.87 & 6.751 & 9.07 & 367.0961 & Sanaganone & {$[\mathrm{M}+\mathrm{Na}]^{+}$} & 2.00 \\
\hline & & & & & & & & 4',6'-Dihydroxy-2'-methoxyacetophenone 6'-glucoside & {$[\mathrm{M}+\mathrm{Na}]^{+}$} & -3.90 \\
\hline 4 & 10.11 & 9.39 & 13.37 & 17.95 & 6.538 & 8.66 & 475.0791 & Unknown & & \\
\hline \multirow[t]{3}{*}{5} & 12.14 & 12.62 & 15.35 & 18.96 & 6.367 & 9.04 & 385.1076 & $\begin{array}{l}\text { 8-p-Coumaroyl-3,4-dihydro-5,7-dihydroxy-4- } \\
\text { phenylcoumarin }\end{array}$ & $\begin{array}{l}{[\mathrm{M}+\mathrm{H}-} \\
\left.\mathrm{H}_{2} \mathrm{O}\right]^{+}\end{array}$ & 0.00 \\
\hline & & & & & & & & Asp-OHPhe-OH & $\begin{array}{l}{[\mathrm{M}+\mathrm{H}-} \\
\left.\mathrm{H}_{2} \mathrm{O}\right]^{+}\end{array}$ & 4.00 \\
\hline & & & & & & & & Val-His-OH & {$[\mathrm{M}+\mathrm{Na}]^{+}$} & -4.30 \\
\hline 6 & 9.78 & 9.64 & 15.45 & 19.06 & 6.348 & 8.24 & 686.1217 & Unknown & & \\
\hline 7 & 9.61 & 9.87 & 12.50 & 16.28 & 6.212 & 8.69 & 518.1319 & Unknown & & \\
\hline 8 & 6.18 & 10.02 & 12.87 & 17.19 & 6.208 & 9.40 & 475.0599 & S-antazirine & $\begin{array}{l}{[\mathrm{M}+\mathrm{H}-} \\
\left.\mathrm{H}_{2} \mathrm{O}\right]^{+}\end{array}$ & 0.90 \\
\hline 9 & 14.05 & 13.87 & 16.81 & 20.43 & 6.182 & 8.23 & 165.0072 & Chloro-methylphenol & {$[\mathrm{M}+\mathrm{Na}]^{+}$} & -0.60 \\
\hline \multirow[t]{2}{*}{10} & 8.84 & 10.48 & 14.56 & 19.00 & 6.164 & 8.19 & 209.0358 & Ethyl-2-amino-4-methyl-Thiazole-5-Carboxylate & {$[\mathrm{M}+\mathrm{Na}]^{+}$} & 0.30 \\
\hline & & & & & & & & 2-Chloro-1,3-dimethoxy-5-methylbenzene & {$[\mathrm{M}+\mathrm{Na}]^{+}$} & 1.80 \\
\hline \multirow[t]{2}{*}{11} & 13.02 & 12.90 & 15.26 & 18.79 & 6.139 & 8.73 & 336.1393 & Aspartylglycosamine & {$[\mathrm{M}+\mathrm{H}]^{+}$} & -0.80 \\
\hline & & & & & & & & Methionine Tryptophan dipeptide & {$[\mathrm{M}+\mathrm{H}]^{+}$} & 1.70 \\
\hline \multirow[t]{2}{*}{12} & 4.29 & 8.58 & 11.92 & 16.21 & 6.091 & 9.40 & 477.0582 & Cyanidin-3-arabinoside & {$[\mathrm{M}+\mathrm{Na}]^{+}$} & 2.30 \\
\hline & & & & & & & & $\begin{array}{l}\text { 1. 5-Amino-4-imidazole-N-succinocarboxamide } \\
\text { ribonucleotide }\end{array}$ & {$[\mathrm{M}+\mathrm{Na}]^{+}$} & -4.70 \\
\hline 13 & 11.17 & 11.23 & 14.77 & 18.62 & 6.018 & 7.84 & 197.0354 & Unknown & & \\
\hline \multirow[t]{4}{*}{14} & 9.78 & 9.79 & 15.86 & 19.93 & 5.939 & 8.69 & 193.0390 & $\begin{array}{l}\text { 2,3-Diketo-L-gulonate (isomers of trihydroxy- } \\
\text { dioxohexanoate) }\end{array}$ & {$[\mathrm{M}+\mathrm{H}]^{+}$} & 4.70 \\
\hline & & & & & & & & $\begin{array}{l}\text { 2,5-Didehydro-D-gluconate (isomers of trihydroxy- } \\
\text { dioxohexanoate) }\end{array}$ & {$[\mathrm{M}+\mathrm{H}]^{+}$} & 4.70 \\
\hline & & & & & & & & $\begin{array}{l}\text { 5-dehydro-4-deoxy-D-glucarate (isomers of dihydroxy- } \\
\text { oxohexanedioate) }\end{array}$ & {$[\mathrm{M}+\mathrm{H}]^{+}$} & 4.70 \\
\hline & & & & & & & & $\begin{array}{l}\text { 2-dehydro-3-deoxy-D-glucarate (isomers of dihydroxy- } \\
\text { oxohexanedioate) }\end{array}$ & {$[\mathrm{M}+\mathrm{H}]^{+}$} & 4.70 \\
\hline 15 & 13.17 & 12.33 & 15.60 & 19.30 & 5.890 & 8.74 & 324.1363 & Tryptophan Proline dipeptide & {$[\mathrm{M}+\mathrm{Na}]^{+}$} & 4.40 \\
\hline 16 & 9.44 & 9.33 & 13.67 & 17.22 & 5.869 & 8.24 & 688.1193 & Unknown & & \\
\hline 17 & 10.47 & 12.50 & 11.67 & 15.63 & 5.738 & 8.26 & 404.1056 & Asn-Tyr-OH & {$[\mathrm{M}+\mathrm{H}]^{+}$} & -3.20 \\
\hline 18 & 13.05 & 12.28 & 13.52 & 17.48 & 5.712 & 8.22 & 424.0814 & Xanthommatin & {$[\mathrm{M}+\mathrm{H}]^{+}$} & 3.90 \\
\hline \multirow[t]{2}{*}{19} & 11.35 & 5.29 & 12.98 & 18.44 & 5.697 & 9.05 & 407.0891 & 7-Chloro-3,4',5,6,8-pentamethoxyflavone & {$[\mathrm{M}+\mathrm{H}]^{+}$} & -0.10 \\
\hline & & & & & & & & $\begin{array}{l}\text { 2-[6-(4'-hydroxy)phenoxy-3H-xanthene-3-on-9-yl]benzoic } \\
\text { acid }\end{array}$ & $\stackrel{\left[\mathrm{M}+\mathrm{H}_{-}^{-}\right.}{\left.\mathrm{H}_{2} \mathrm{O}\right]^{+}}$ & 2.80 \\
\hline \multirow[t]{3}{*}{20} & 14.10 & 13.76 & 13.08 & 15.32 & 5.661 & 6.46 & 181.0031 & 5-Chloro-3-methylcatechol & {$[\mathrm{M}+\mathrm{Na}]^{+}$} & 0.40 \\
\hline & & & & & & & & 2-Oxopropyl-CoM & $\begin{array}{l}{\left[\mathrm{M}+\mathrm{H}_{-}^{-}\right.} \\
\left.\mathrm{H}_{2} \mathrm{O}\right]^{+}\end{array}$ & 3.80 \\
\hline & & & & & & & & Urea phosphate salt & {$[\mathrm{M}+\mathrm{Na}]^{+}$} & 4.60 \\
\hline 21 & 14.02 & 13.27 & 14.63 & 16.63 & 5.645 & 9.05 & 403.1393 & 2',4',6'-Trihydroxydihydrochalcone 2'-glucoside & & 0.00 \\
\hline
\end{tabular}


Table 2 Putative metabolites in ESI+ (Continued)

\begin{tabular}{|c|c|c|c|c|c|c|c|c|c|c|}
\hline & $\begin{array}{l}\text { NO } \\
\text { LIP } \\
\text { INI }\end{array}$ & $\begin{array}{l}\text { LIP } \\
\text { INI }\end{array}$ & $\begin{array}{l}\text { NO } \\
\text { LIP } \\
\text { FIN }\end{array}$ & $\begin{array}{l}\text { LIP } \\
\text { FIN }\end{array}$ & $\begin{array}{l}\text { VIP } \\
\text { score }\end{array}$ & $\begin{array}{l}\text { RT } \\
(\min )\end{array}$ & $\begin{array}{l}\text { Detected } \\
\text { mass } \\
(\mathrm{m} / \mathrm{z})\end{array}$ & Putative metabolites & Assignation & $\begin{array}{l}\text { Mass difference } \\
(\mathrm{mDa})\end{array}$ \\
\hline & & & & & & & & & $\begin{array}{l}{[\mathrm{M}+\mathrm{H}-} \\
\left.\mathrm{H}_{2} \mathrm{O}\right]^{+}\end{array}$ & \\
\hline & & & & & & & & Rhaponticin & $\begin{array}{l}{[\mathrm{M}+\mathrm{H}-} \\
\left.\mathrm{H}_{2} \mathrm{O}\right]^{+}\end{array}$ & 0.00 \\
\hline & & & & & & & & Glycyphyllin & $\begin{array}{l}{[\mathrm{M}+\mathrm{H}-} \\
\left.\mathrm{H}_{2} \mathrm{O}\right]^{+}\end{array}$ & 0.00 \\
\hline & & & & & & & & 4,2'-Dihydroxychalcone 4-glucoside & {$[\mathrm{M}+\mathrm{H}]^{+}$} & 0.60 \\
\hline & & & & & & & & 7-Hydroxyflavanone beta-D-glucopyranoside & {$[\mathrm{M}+\mathrm{H}]^{+}$} & 0.60 \\
\hline \multirow[t]{4}{*}{22} & 11.41 & 10.16 & 12.52 & 17.13 & 5.594 & 8.27 & 425.0803 & 5-Demethylmelibentin & {$[\mathrm{M}+\mathrm{Na}]^{+}$} & -4.00 \\
\hline & & & & & & & & Gossypetin 3,7,3'-trimethyl ether 8-acetate & {$[\mathrm{M}+\mathrm{Na}]^{+}$} & -4.00 \\
\hline & & & & & & & & $5,2^{\prime}, 5^{\prime}$-Trihydroxy-3,7,8-trimethoxyflavone 2'-acetate & {$[\mathrm{M}+\mathrm{Na}]^{+}$} & -4.00 \\
\hline & & & & & & & & Pelargonidin 3-arabinoside & {$[\mathrm{M}+\mathrm{Na}]^{+}$} & -4.00 \\
\hline 23 & 9.95 & 9.65 & 13.74 & 17.65 & 5.569 & 8.21 & 730.1485 & p-Coumaroyl vitisin A & {$[\mathrm{M}+\mathrm{Na}]^{+}$} & -1.90 \\
\hline 24 & 10.09 & 10.10 & 11.21 & 14.66 & 5.563 & 7.09 & 302.0256 & Unknown & & \\
\hline \multirow[t]{2}{*}{25} & 9.61 & 10.26 & 9.90 & 15.94 & 5.557 & 6.51 & 239.0457 & Bisnorbiotin & {$[\mathrm{M}+\mathrm{Na}]^{+}$} & -0.40 \\
\hline & & & & & & & & D-erythro-1-(Imidazol-4-y|)glycerol 3-phosphate & {$[\mathrm{M}+\mathrm{H}]^{+}$} & 3.00 \\
\hline 26 & 9.59 & 9.00 & 13.70 & 17.25 & 5.535 & 8.24 & 687.1237 & Isorhamnetin 3-(4"-sulfatorutinoside) & $\begin{array}{l}{[\mathrm{M}+\mathrm{H}-} \\
\left.\mathrm{H}_{2} \mathrm{O}\right]^{+}\end{array}$ & 0.60 \\
\hline \multirow[t]{2}{*}{27} & 11.46 & 11.12 & 13.15 & 17.09 & 5.496 & 7.82 & 179.0236 & Tetrahydroxypteridine & $\begin{array}{l}{[\mathrm{M}+\mathrm{H}-} \\
\left.\mathrm{H}_{2} \mathrm{O}\right]^{+}\end{array}$ & 0.60 \\
\hline & & & & & & & & Xanthine-8-carboxylate & $\begin{array}{l}{[\mathrm{M}+\mathrm{H}-} \\
\left.\mathrm{H}_{2} \mathrm{O}\right]^{+}\end{array}$ & 0.60 \\
\hline 28 & 8.41 & 8.80 & 12.76 & 16.92 & 5.460 & 8.23 & 286.0291 & Unknown & & \\
\hline
\end{tabular}

The data in LIP INI, NO LIP INI, LIP FIN and NO LIP FIN columns refers to mean intensity of metabolites and are presented as log 2

Abbreviations: $n d$ no detected, $R T$ retention time, VIP variable importance in projection

Table 3 Putative metabolites in ESI-

\begin{tabular}{|c|c|c|c|c|c|c|c|c|c|c|}
\hline & $\begin{array}{l}\text { NO } \\
\text { LIP } \\
\text { INI }\end{array}$ & $\begin{array}{l}\text { LIP } \\
\text { INI }\end{array}$ & $\begin{array}{l}\text { NO } \\
\text { LIP } \\
\text { FIN }\end{array}$ & $\begin{array}{l}\text { LIP } \\
\text { FIN }\end{array}$ & VIP & $\begin{array}{l}\text { RT } \\
(\min )\end{array}$ & $\begin{array}{l}\text { Detected mass } \\
(\mathrm{m} / \mathrm{z})\end{array}$ & Putative metabolites & Assignation & $\begin{array}{l}\text { Mass difference } \\
(\mathrm{mDa})\end{array}$ \\
\hline 1 & nd & nd & 15.10 & 19.27 & 4.552 & 9.06 & 385.0878 & Phe-Met-OH & {$\left[\mathrm{M}-\mathrm{H}_{2} \mathrm{O}-\mathrm{H}\right]^{-}$} & 2.00 \\
\hline \multirow[t]{6}{*}{2} & nd & nd & 16.02 & 19.71 & 4.487 & 9.04 & 767.1824 & Kaempferol 3-(2"-(E)-feruloylgalactosyl-glucoside) & {$\left[\mathrm{M}-\mathrm{H}_{2} \mathrm{O}-\mathrm{H}\right]^{-}$} & 0.10 \\
\hline & & & & & & & & Isoorientin 2"-(feruloyl-glucoside) & {$\left[\mathrm{M}-\mathrm{H}_{2} \mathrm{O}-\mathrm{H}\right]^{-}$} & 0.10 \\
\hline & & & & & & & & Peonidin 3-[6-(3-glucosylcaffeyl)glucoside] & {$\left[\mathrm{M}-\mathrm{H}_{2} \mathrm{O}-\mathrm{H}\right]^{-}$} & 0.10 \\
\hline & & & & & & & & Petunidin 3-(6"-p-coumarylglucoside)-glucoside & {$\left[\mathrm{M}-\mathrm{H}_{2} \mathrm{O}-\mathrm{H}\right]^{-}$} & 0.10 \\
\hline & & & & & & & & Isoorientin 4'-O-glucoside 2"-O-(E)-ferulate & {$\left[\mathrm{M}-\mathrm{H}_{2} \mathrm{O}-\mathrm{H}\right]^{-}$} & 0.10 \\
\hline & & & & & & & & Cyanidin 3-(6"-ferulylglucoside)-glucoside & {$\left[\mathrm{M}-\mathrm{H}_{2} \mathrm{O}-\mathrm{H}\right]^{-}$} & 0.10 \\
\hline 3 & 11.01 & 10.86 & 11.99 & 15.37 & 4.465 & 8.29 & 821.1515 & Unknown & & \\
\hline \multirow[t]{3}{*}{4} & 14.82 & 15.42 & 18.71 & 22.55 & 4.348 & 9.05 & 383.0907 & $\begin{array}{l}\text { 8-p-Coumaroyl-3,4-dihydro-5,7-dihydroxy-4- } \\
\text { phenylcoumarin }\end{array}$ & {$\left[\mathrm{M}-\mathrm{H}_{2} \mathrm{O}-\mathrm{H}\right]^{-}$} & -1.20 \\
\hline & & & & & & & & Asp-OHPhe-OH & {$\left[\mathrm{M}-\mathrm{H}_{2} \mathrm{O}-\mathrm{H}\right]^{-}$} & 2.80 \\
\hline & & & & & & & & Val-His-OH & {$\left[\mathrm{M}-\mathrm{H}_{2} \mathrm{O}-\mathrm{H}\right]^{-}$} & 2.80 \\
\hline 5 & nd & nd & 13.92 & 17.51 & 4.127 & 9.05 & 769.1913 & Unknown & & \\
\hline 6 & nd & nd & 10.30 & 16.10 & 4.063 & 9.05 & 481.0584 & Unknown & & \\
\hline
\end{tabular}

The data in LIP INI, NO LIP INI, LIP FIN and NO LIP FIN columns refers to mean intensity of metabolites and are presented as log 2 Abbreviations: $n d$ no detected, $R T$ retention time, VIP variable importance in projection 
Table 4 Correlation analysis between putative metabolites and biochemical measurements

\begin{tabular}{llll}
\hline Putative metabolites & Biochemical measurements & rho & $\mathrm{p}$ \\
\hline Metabolite 14 ESI+ & $\Delta$ FFA & -0.3621 & 0.0453 \\
& Endpoint $\beta$-hydroxybutyrate & -0.3601 & 0.0466 \\
& Endpoint ADMA & -0.4397 & 0.0133 \\
& Endpoint SOD & 0.4036 & 0.0270
\end{tabular}

rho: Spearman correlation coefficient; $p<0.05$ was considered significant; $\Delta$ : change: [(endpoint-baseline) / baseline] $\times 100$

Abbreviations: $E S I+$ positive electrospray ionization, $H O M A-I R$ homeostasis model assessment, FFA free fatty acids, ADMA asymmetric dimethylarginine, $S O D$ superoxide dismutase

role of obesity itself, since amino acids, fatty acids and other species may be involved [54-56].

In this case, the discriminant metabolites are increased in LIP group at endpoint with respect to the other groups, suggesting that protein/lipid catabolism is increased with $\alpha$-LA supplementation. In this context, previous studies have suggested lipolytic actions of $\alpha$-LA both in cultured adipocytes [57] and after dietary supplementation [19]. Moreover, $\alpha$-LA administration has been reported to affect glucose metabolism by inhibiting glycolysis and Thr-Gly-Ser pathways [58] as well as providing carbon groups to the tricarboxylic acid cycle [59]. Furthermore, $\alpha$-LA (combined with flaxseed oil) appeared to ameliorate hepatic oxidative stress and lipid accumulation [60] or decrease LDL oxidation [61] in addition to its recognized antioxidant properties [37]. Indeed, antioxidants may modulate oxidative stress and inflammatory responses through interrelated mechanisms [62]. Therefore, dietary $\alpha$-LA may collaborate with endogenous antioxidant machineries on preventive or repair system defenses, where interactions and overlappings with other exogenous antioxidants may occur [63].

The presence of 2,3-diketo-L-gulonate (one isomer of trihydroxy-dioxohexanoate) in urine [64] has been previously described, and has been characterized as an intermediary metabolite of the ascorbic acid metabolism [65, 66]. Plasma levels of $\alpha$-LA and ascorbic acid have been linked in previous studies $[67,68]$, revealing that $\alpha$-LA may improve endogenous ascorbate levels indirectly by inducing its uptake from the blood plasma [67] or by affecting ascorbate recycling [65]. This fact might be associated with antioxidant properties of both compounds, since $\alpha$ LA acts as antioxidant not only directly through radical quenching and metal chelation, but also indirectly through recycling of other antioxidants such as ascorbate [68] or by increasing the expression of antioxidant enzymes [69]. Furthermore, other isomers such as 2,5-didehydro-D-gluconate (isomers of trihydroxy-dioxohexanoate) or dihydroxy-oxohexanedioate (5-dehydro-4-deoxy-D-glucarate; 2-dehydro-3-deoxy-D-glucarate) with compatible $\mathrm{m} /$ $\mathrm{z}$ values have been related with ascorbic acid synthesis and degradation [70]. Other metabolites that initially showed similar theoretical mass but discarded after appropriate validation analyses were citrate/isocitrate, succinate and glucaric acid lactone. Therefore, all these findings could explain the presence of an ascorbate intermediate in urine in a supplementary nutritional intervention trial, contributing to overcome and complement the antioxidant properties of ascorbic acid as a reducing agent, which donate electron to various enzymatic and non-enzymatic reaction related to oxidative stress [71]. Interestingly, both $\alpha$-LA and vitamin $C$ administration have shown reasonable evidence for obesity management [72]. Another issue to be considered is that the structure of ascorbic acid $\left(\mathrm{C}_{6} \mathrm{H}_{8} \mathrm{O}_{6}\right)$ is close to glucose/monosaccharides, while $\alpha$ LA has regulatory functions on the Krebs cycle [37, 73].

Correlations between metabolite 14 and ADMA or SOD could be mediated by the antioxidant power of $\alpha$ LA, previously described in several studies [68], and also involving benefits on body adiposity $[18,21]$, where interactions with vitamin $\mathrm{C}$ cannot be discarded [74]. Finally, correlations metabolite 14 with FFA and hydroxybutyrate [75] could be associated with less BMI observed in $\alpha$-LA supplementation groups at endpoint.

\section{Conclusions}

Summing up, this metabolomic approach supports the hypothesis that the beneficial effects of $\alpha$-LA administration on body weight reduction may be partly explained by the antioxidant properties of this organosulfur carboxylic acid, where interactions with ascorbic acid should be taken into account mediated by trihydroxydioxohexanoate or dihydroxy-oxohexanedioate.

\section{Additional file}

Additional file 1 : Figure S1. Principal component analysis (PCA) of untargeted metabolomics analysis of urine samples, including CONTROL (red), EPA (green), LA (dark blue), EPA+LA (light blue) groups. A) PCA in positive ionization mode (ESI+). B) PCA in negative ionization mode (ESI-) (DOCX 199 kb)

\section{Abbreviations}

a-LA: a-lipoic acid; ADMA: asymmetric dimethylarginine; BMI: body mass index; EPA: eicosapentaenoic acid; ESI: electrospray ionization; FFA: free fatty acids; HPLC-TOF-MS: liquid chromatography coupled with time of flight mass spectrometry; incremental area under the curve HOMA-IR: homeostasis model assessment; LIP: lipoic group; MetS: metabolic syndrome; NO LIP: no lipoic group; PCA: principal component analysis; PLS-DA: partial least squares-discriminant analysis; SOD: superoxide dismutase; VIP: variable importance in projection

Funding

This study was supported by Ministry of Economy and Competitiveness (MINECO) from the Government of Spain (ref. AGL 2009-10873/ALI and BFU2012-36089) and CIBERobn. AE Huerta was supported by a predoctoral grant from "Asociación de Amigos de la Universidad de Navarra".

Availability of data and materials

Data are available from the corresponding author on reasonable request. 


\section{Authors' contributions}

ARH, AEH, CJGN; MJMA and JAM contributed to the work done in this manuscript. AEH, MJMA and JAM: Contributed to the study design. ARH and AEH: Contributed to the analysis and statistical analysis. ARH, ORL and JAM: Contributed to the interpretation of the data and drafting of the manuscript. AEH, CJGN, ORL and MJMA: Contributed to critical revision of the manuscript. All authors have read and approved the final manuscript

\section{Ethics approval and consent to participate}

The study was approved by the Research Committee of the University of Navarra No. 007/2009 and recorded at clinicaltrials.gov as NCT01138774. All volunteers signed the informed consent before being recruited in the trial. The intervention was conducted in accordance with the latest Helsinki Declaration guidelines.

\section{Competing interests}

EPA and sunflower oil capsules were provided by Solutex (Madrid, Spain). Solutex had no role in the study design, data collection, analysis and interpretation, or writing of the manuscript. The authors have declared no conflict of interest.

\section{Publisher's Note}

Springer Nature remains neutral with regard to jurisdictional claims in published maps and institutional affiliations.

\section{Author details}

${ }^{1}$ Centre for Nutrition Research, University of Navarra, Pamplona, Spain. ${ }^{2}$ Department of Nutrition, Food Science, and Physiology, University of Navarra, Pamplona, Spain. ${ }^{3}$ Spanish Biomedical Research Centre in Physiopathology of Obesity and Nutrition (CIBERobn), Institute of Health Carlos III (ISCIII), Madrid, Spain. ${ }^{4}$ Navarra Institute for Health Research (IDISNA), Pamplona, Spain. ${ }^{5}$ Madrid Institute of Advanced Studies (IMDEA Food), Madrid, Spain.

Received: 19 February 2018 Accepted: 19 April 2018 Published online: 09 May 2018

\section{References}

1. Dudzik D, Barbas-Bernardos C, García C, Barbas C. Quality assurance procedures for mass spectrometry untargeted metabolomics. A review. J Pharm Biomed Anal. 2018;147:149-73.

2. Metabolomics NCB. Metabolic diseases: where do we stand? Cell Metab. 2017;25(1):43-56.

3. Shah $\mathrm{SH}$, Kraus WE, Newgard CB. Metabolomic profiling for the identification of novel biomarkers and mechanisms related to common cardiovascular diseases: form and function. Circulation. 2012;126(9):1110-20.

4. Alonso A, Marsal S, Julià A. Analytical methods in untargeted metabolomics: state of the art in 2015. Front Bioeng Biotechnol. 2015;3:23.

5. Llorach R, Garcia-Aloy M, Tulipani S, Vazquez-Fresno R, Andres-Lacueva C. Nutrimetabolomic strategies to develop new biomarkers of intake and health effects. J Agric Food Chem. 2012;60:8797-808.

6. Johnson AR, Makowski L. Nutrition and metabolic correlates of obesity and inflammation: clinical considerations. J Nutr. 2015;145(5):1131S-6S

7. Ramos-Lopez O, Milagro Fl, Allayee H, Chmurzynska A, Choi MS, Curi R, De Caterina R, Ferguson LR, Goni L, Kang JX, Kohlmeier M, Marti A, Moreno LA, Pérusse L, Prasad C, Qi L, Reifen R, Riezu-Boj Jl, San-Cristobal R, Santos JL, Martínez JA. Guide for current Nutrigenetic, nutrigenomic, and Nutriepigenetic approaches for precision nutrition involving the prevention and Management of Chronic Diseases Associated with obesity. J Nutrigenet Nutrigenomics. 2017;10(1-2):43-62.

8. Christian LM, Young AS, Mitchell AM, Belury MA, Gracious BL, Arnold LE, Fristad MA. Body weight affects $\omega-3$ polyunsaturated fatty acid (PUFA) accumulation in youth following supplementation in post-hoc analyses of a randomized controlled trial. PLoS One. 2017;12(4):e0173087.

9. Bondia-Pons I, Pöhö P, Bozzetto L, Vetrani C, Patti L, Aura AM, Annuzzi G, Hyötyläinen T, Rivellese AA, Orešič M. Isoenergetic diets differing in their in n-3 fatty acid and polyphenol content reflect different plasma and HDLfraction lipidomic profiles in subjects at high cardiovascular risk. Mol Nutr Food Res. 2014;58(9):1873-82.

10. Fernández-Galilea M, Prieto-Hontoria PL, Martínez JA, Moreno-Aliaga MJ. Antiobesity effects of a-lipoic acid supplementation. Clin Lipidol. 2013;8:371-83.
11. Vidovic B, Milovanovic S, Dordevic B, Kotur-Stevuljevic J, Stefanovic A, Ivanisevic J, et al. Effect of alpha-lipoic acid supplementation on oxidative stress markers and antioxidative defense in patients with schizophrenia. Psychiatr Danub. 2014;26:205-13.

12. Prieto-Hontoria PL, Pérez-Matute $P$, Fernández-Galilea M, Barber A, Martínez JA, Moreno-Aliaga MJ. Lipoic acid prevents body weight gain induced by a high fat diet in rats: effects on intestinal sugar transport. J Physiol Biochem. 2009;65(1):43-50.

13. Valdecantos MP, Pérez-Matute P, González-Muniesa P, Prieto-Hontoria PL, Moreno-Aliaga MJ, Martínez JA. Lipoic acid improves mitochondrial function in nonalcoholic steatosis through the stimulation of sirtuin 1 and sirtuin 3 . Obesity. 2012;20(10):1974-83.

14. Fernández-Galilea M, Pérez-Matute P, Prieto-Hontoria PL, Sáinz N, LópezYoldi M, Houssier M, Martínez JA, Langin D, Moreno-Aliaga MJ. a-lipoic acid reduces fatty acid esterification and lipogenesis in adipocytes from overweight/obese subjects. Obesity. 2014;22(10):2210-5.

15. Namazi N, Larijani B, Azadbakht L. Alpha-lipoic acid supplement in obesity treatment: a systemic review and meta-analysis of clinical trials. Clin Nutr. 2017;8:S0261-5614.

16. Kucukgoncu S, Zhou E, Lucas KB, Tek C. Alpha-lipoic acid (ALA) as a supplementation for weight loss: results from a meta-analysis of randomized controlled trials. Obes Rev. 2017;18:594-601.

17. Lorente-Cebrián S, Costa AG, Navas-Carretero S, Zabala M, Martínez JA, Moreno-Aliaga MJ. Role of omega-3 fatty acids in obesity, metabolic syndrome, and cardiovascular diseases: a review of the evidence. J Physiol Biochem. 2013:69:633-51.

18. Huerta AE, Prieto-Hontoria PL, Sáinz N, Martínez JA. Moreno-Aliaga MJ supplementation with a-lipoic acid alone or in combination with Eicosapentaenoic acid modulates the inflammatory status of healthy overweight or obese women consuming an energy-restricted diet. J Nutr. 2016;9:889S-96S.

19. Huerta AE, Prieto-Hontoria PL, Fernández-Galilea M, Escoté X, Martínez JA, Moreno-Aliaga MJ. Effects of dietary supplementation with EPA and/or alipoic acid on adipose tissue transcriptomic profile of healthy overweight/ obese women following a hypocaloric diet. Biofactors. 2017;43(1):117-31.

20. Dasilva G, Pazos M, García-Egido E, Pérez-Jiménez J, Torres JL, Giralt M, Nogués MR, Medina I. Lipidomics to analyze the influence of diets with different EPA:DHA ratios in the progression of metabolic syndrome using SHROB rats as a model. Food Chem. 2016;205(15):196-203.

21. Huerta AE, Navas-Carretero S, Prieto-Hontoria PL, Martínez JA, MorenoAliaga MJ. Effects of a-lipoic acid and eicosapentaenoic acid in overweight and obese women during weight loss. Obesity. 2015;23(2):313-21.

22. De la Iglesia R, Lopez-Legarrea P, Abete I, Bondia-Pons I, Navas-Carretero $S$, Forga L, Martínez JA, Zulet MAA. New dietary strategy for long-term treatment of the metabolic syndrome is compared with the American Heart Association (AHA) guidelines: the MEtabolic syndrome REduction in NAvarra (RESMENA) project. Br J Nutr. 2014;111(4):643-52.

23. Huerta $A E$, Prieto-Hontoria PL, Fernández-Galilea M, Sáinz N, Cuervo M, Martínez JA, Moreno-Aliaga MJ. Circulating irisin and glucose metabolism in overweight/obese women: effects of a-lipoic acid and eicosapentaenoic acid. J Physiol Biochem. 2015;71:547-58.

24. Matthews DR, Hosker JP, Rudenski AS, Naylor BA, Treacher DF, Turner RC. Homeostasis model assessment: insulin resistance and beta-cell function from fasting plasma glucose and insulin concentrations in man. Diabetologia. 1985;28(7):412-9.

25. Puchau B, Zulet MA, Urtiaga G, Navarro-Blasco I, Martínez JA. Asymmetric dimethylarginine association with antioxidants intake in healthy young adults: a role as an indicator of metabolic syndrome features. Metabolism. 2009;58(10):1483-8

26. Ho E, Galougahia KK, Liu CC, Bhindi R, Figtree GA. Biological markers of oxidative stress: applications to cardiovascular research and practice. Redox Biol. 2013;1(1):483-91.

27. Ibero-Baraibar I, Romo-Hualde A, González-Navarro CJ, Zulet MA, Martínez JA. Urinary metabolomic profile following the intake of meals supplemented with cocoa extract in middle-aged obese subjects. Food Funct. 2016;7(4):1924-31.

28. Gika HG, Theodoridis GA, Wingate JE, Wilson ID. Within-day reproducibility of an HPLC-MS-based method for metabonomic analysis: application to human urine. J Proteome Res. 2007:6:3291-303.

29. Llorach R, Urpi-Sarda M, Jauregui O, Monagas M, Andres-Lacueva C. An LCMS-based metabolomics approach for exploring urinary metabolome modifications after cocoa consumption. J Proteome Res. 2009;8:5060-8. 
30. Benton HP, Ivanisevic J, Mahieu NG, Kurczy ME, Johnson CH, Franco L, Rinehart D, Valentine E, Gowda H, Ubhi BK, Tautenhahn R, Gieschen A Fields MW, Patti GJ, Siuzdak G. Autonomous metabolomics for rapid metabolite identification and global profiling. Anal Chem. 2015;87:884-91.

31. Gowda H, Ivanisevic J, Johnson CH, Kurczy ME, Benton HP, Rinehart D, Nguyen T, Ray J, Kuehl J, Arevalo B, Westenskow PD, Wang J, Arkin AP, Deutschbauer AM, Patti GJ, Siuzdak G. Interactive XCMS online: simplifying advanced metabolomic data processing and subsequent statistical analyses. Anal Chem. 2014;86(14):6931-9.

32. Zhu ZJ, Schultz AW, Wang J, Johnson CH, Yannone SM, Patti GJ, Siuzdak G. Liquid chromatography quadrupole time-of-flight mass spectrometry characterization of metabolites guided by the METLIN database. Nat Protoc. 2013;8(3):451-60.

33. Li S, Park Y, Duraisingham S, Strobel FH, Khan N, Soltow QA, Jones DP, Pulendran B. Predicting network activity from high throughput metabolomics. PLoS Comput Biol. 2013;9(7):e1003123.

34. Tautenhahn R, Cho K, Uritboonthai W, Zhu Z, Patti GJ, Siuzdak G. An accelerated workflow for untargeted metabolomics using the METLIN database. Nat Biotechnol. 2012;30:826-8.

35. Farrés M, Piña B, Tauler R. Chemometric evaluation of Saccharomyces cerevisiae metabolic profiles using LC-MS. Metabolomics. 2015;11:210-24.

36. Struck-Lewicka W, Kordalewska M, Bujak R, Yumba Mpanga A, Markuszewski M, Jacyna J, Matuszewski M, Kaliszan R, Markuszewski MJ. Urine metabolic fingerprinting using LC-MS and GC-MS reveals metabolite changes in prostate cancer: a pilot study. J Pharm Biomed Anal. 2015;111:351-61.

37. Valdecantos MP, Pérez-Matute $P$, Quintero $P$, Martínez JA, Vitamina C. Resveratrol and lipoic acid actions on isolated rat liver mitocondria: all antioxidants but different. Redox Rep. 2010;15(5):207-2016

38. Leslie MA, Cohen DJ, Liddle DM, Robinson LE, Ma DW. A review of the effect of omega-3 polyunsaturated fatty acids on blood triacylgrlycero levels in normolipidemic and borderline hyperlipidemic individuals. Lipids Health Dis. 2015;14:53.

39. Yang ZH, Emma-Okon B, Remaley AT. Dietary marine-derived long-chain monounsaturated fatty acids and cardiovascular disease risk: a mini review. Lipids Health Dis. 2016;15(1):201.

40. Fitó M, Melander O, Martínez JA, Toledo E, Carpéne C, Corella D. Advances in integrating traditional and omic biomarkers when analyzing the effects of the Mediterranean diet intervention in cardiovascular prevention. Int J Mol Sci. 2016;17:1469.

41. Sun JH, Liu X, Cong LX, Li H, Zhang CY, Chen JG, Wang CM. Metabolomics study of the therapeutic mechanism of Schisandra Chinensis lignans in diets-induced hyperlipidemia mice. Lipids Health Dis. 2017;16(1):145.

42. Etxeberria U, Arias N, Boque N, Romo-Hualde A, Macarulla MT, Portillo MP, Milagro Fl, Martínez JA. Metabolic faecal fingerprinting of trans-resveratrol and quercitin following a high fat sucrose dietary model using liquid chromatography coupled to high-resolution mass spectrometry. Food Funct. 2015;6:2758-67.

43. Bondia Pons I, Martinez JA, de la Iglesia R, Lopez-Legarrea P, Poutanen K, Hanhineva K, MdeL Z. Effects of short and long-term Mediterranean-based dietary treatment on plasma LC-QTOF/MS metabolic profiling of subjects with metabolic syndrome features: the metabolic syndrome reduction in Navarra (RESMENA) randomized controlled trial. Mol Nutr Food Res. 2015;59(4):711-28.

44. Perez-Cornago A, Brennan L, Ibero-Baraibar I, Hermsdorff HH, O'Gorman A, Zulet MA, Martínez JA. Metabolomics identifies changes in fatty acid and amino acid profiles in serum of overweight older adults following a weight loss intervention. J Physiol Biochem. 2014;70(2):593-602.

45. Tulipani S, Griffin J, Palau-Rodriguez M, Mora-Cubillos X, Bernal-Lopez RM, Tinahones FJ, Corkey BE, Andres-Lacueva C. Metabolomics-guided insights on bariatric surgery versus behavioral interventions for weight loss. Obesity. 2016;24(12):2451-66

46. Yu D, Moore SC, Matthewa CE, Xiang YB, Zhang X, Gao YT, Zheng W, Shu $X O$. Plasma metabolomic profiles in association with type 2 diabetes risk and prevalence in Chinese adults. Metabolomics. 2016;12:3.

47. Kaikkonen JE, Würtz $P$, Suomela E, Lehtovirta M, Kangas AJ, Jula A, Mikkilä V, Viikari JS, Juonala M, Rönnemaa T, Hutri-Kähönen N, Kähönen M, Lehtimäki T, Soininen P, Ala-Korpela M, Raitakari OT. Metabolic profiling of fatty liver in young and middle-aged adults: cross-sectional and prospective analyses of the Young Finns Study. Hepatology. 2017;65(2):491-500.

48. Ubhi BK, Cheng KK, Dong J, Janowitz T, Jodrell D, Tal-Singer R, MacNee W, Lomas DA, Riley JH, Griffin JL, Connor SC. Targeted metabolomics identifies perturbations in amino acid metabolism that sub-classify patients with COPD. Mol BioSyst. 2012;8(12):125-33.
49. Sébédio $\mathrm{JL}$, Polakof S. Using metabolomics to identify biomarkers for metabolic diseases: analytical methods and applications. Metabolomics as a Tool in Nutritional Research, Academic Press Elsevier; 2015. pp. 268. Woodhead Publishing Series in Food Science, Technology and Nutrition, 978-1-78242-084-2.

50. Rauschert S, Uhl O, Koletzko B, Hellmuth C. Metabolomic biomarkers for obesity in humans: a short review. Ann Nutr Metab. 2014;64(3-4):314-24.

51. Zhao Q, Zhu Y, Best LG, Umans JG, Uppal K, Tran VT, Jones DP, Lee ET, Howard BV, Zhao J. Metabolic profiles of obesity in American Indians: the strong heart family study. PLoS One. 2016;11(7):e0159548.

52. Bogl LH, Kaye SM, Rämo JT, Kangas AJ, Soininen P, Hakkarainen A, Lundbom J, Lundbom N, Ortega-Alonso A, Rissanen A, Ala-Korpela M, Kaprio J, Pietilaäinen KH. Adbominal obesity and circulating metabolites: a twin study approach. Metabolism. 2016;65(3):111-21.

53. Sampey BP, Freemerman AJ, Zhang J, Kuan PF, Galanko JA, O'Connell TM, Ilkayeva OR, Muehlbauer MJ, Stevens RD, Newgard CB, Brauer HA, Troester MA, Makowski L. Metabolomic profiling reveals mitochondrial-derived lipid biomarkers that drive obesity-associated inflammation. PLoS One. 2012;7(6):e38812.

54. Moore SC, Matthews CE, Sampson JN, Stolzenberg-Solomon RZ, Zheng W, Cai Q, Tan YT, Chow WH, Ji BT, Liu DK, Xiao Q, Boca SM, Leitzmann MF, Yang G, Xiang YB, Sinha R, Shu XO, Cross AJ. Human metabolic correlates of body mass index. Metabolomics. 2014;10(2):259-69.

55. Murphy RA, Moore SC, Playdon M, Meirelles O, Newman AB, Milijkovic I, Kritchevsky SB, Schwartz A, Goodpaster BH, Sampson J, Cawthon P, Simonsick EM, Gerszten RE, Clish CB, Harris TB. Metabolites associated with lean mass and adiposity in older black men. J Gerontol A Biol Sci Med Sci. 2017;72(10):1352-9.

56. Halama A, Horsch M, Kastenmüller G, Möller G, Kumar P, Prehn C, Laumen $H$, Hauner $H$, Hrabě de Angelis M, Beckers J, Suhre K, Adamski J. Metabolic switch during adipogenesis: from branched chain amino acid catabolism to lipid synthesis. Arch Biochem Biophys. 2016;589:93-107.

57. Fernández-Galilea M, Pérez-Matute P, Prieto-Hontoria PL, Martinez JA, Moreno-Aliaga MJ. Effects of lipoic acid on lipolysis in 3T3-L1 adipocytes. J Lipid Res. 2012;53(11):2296-306.

58. Ikuta N, Chikamoto K, Asano Y, Yasui Y, Yokokawa H, Terao K, Rimbach G, Matsugo S. Time course effect of R-alpha-lipoic acid on cellular metabolomics in cultured hepatoma cells. J Med Food. 2017;20(3):211-22.

59. Bingham PM, Stuart SD, Zachar Z. Lipoic acid and lipoic acid analogs in cancer metabolism and chemotherapy. Expert Rev Clin Pharmacol. 2014; 7(6):837-46

60. Xu J, Gao H, Song L, Yang W, Chen C, Deng Q, Huang Q, Yang J, Huang F. Flaxseed oil and alpha-lipoic acid combination ameliorates hepatic oxidative stress and lipid accumulation in comparison to lard. Lipids Health Dis. 2013; 12:58

61. McNeilly AM, Davison GW, Murphy MH, Nadeem N, Trinick T, Duly E, Novials A, McEneny J. Effect of a-lipoic acid and exercise training on cardiovascular disease risk in obesity with impaired glucose tolerance. Lipids Health Dis. 2011;10:217

62. Bondia-Pons I, Ryan L, Martinez JA. Oxidative stress and inflammation interactions in human obesity. J Physiol Biochem. 2012;68(4):701-11.

63. Pisoschi AM, Pop A. The role of antioxidants in the chemistry of oxidative stress: a review. Eur J Med Chem. 2015;97:55-74.

64. Koshiishi I, Mamura Y, Liu J, Imanari T. Degradation of dehydroascorbate to 2,3-diketogulonate in blood circulation. Biochim Biophys Acta. 1998;1425(1): 209-14.

65. Linster CL, Van Schaftingen E, Biosynthesis VC. Recycling and degradation in mammals. FEBS J. 2007;274(1):1-22.

66. Kalleneri A, Horning D, Pellikka R. Formation of carbon dioxide from ascorbate in man. Am J Clin Nutr. 1985;41:609-13.

67. Petersen Shay K, Moreau RF, Smith EJ, Smith AR, Hagen TM. Alpha-lipoic acid as a dietary supplement: molecular mechanisms and therapeutic potential. Biochim Biophys Acta. 2009;1790(10):1149-60.

68. Packer L, Witt EH, Tritschler HJ. Alpha-lipoic acid as a biological antioxidant. Free Radic Biol Med. 1995;19(2):227-50.

69. Moura FA, de Andrade KQ, dos Santos JC, Goulart MO. Lipoic acid: its antioxidant and anti-inflammatory role and clinical applications. Curr Top Med Chem. 2015;15(5):458-83.

70. De Tullio MC. The mystery of vitamin C. Nature Education. 2010;3(9):48.

71. Garcia-Diaz DF, Lopez-Legarrea P, Quintero P, Martinez JA, Vitamin C. In the treatment and/or prevention of obesity. J Nutr Sci Vitaminol (Tokyo). 2014; 60(6):367-79. 
72. Abdali D, Samson SE, Grover AK. How effective are antioxidant supplements in obesity and diabetes? Med Princ Pract. 2015;24(3):201-15.

73. Ryan DG, LAJ O'N. Krebs cycle rewired for macrophage and dendritic cell effector functions. FEBS Lett. 2017;591(19):2992-3006.

74. Campión J, Milagro Fl, Fernández D, Martínez JA, Vitamin C.

Supplementation influences body fat mass and steroidogenesis-related genes when fed a high-fat diet. Int J Vitam Nutr Res. 2008;78(2):87-95.

75. Chearskul S, Delbridge E, Shulkes A, Proietto J, Kriketos A. Effect of weight loss and ketosis on postprandial cholecystokinin and free fatty acid concentrations. Am J Clin Nutr. 2008;87(5):1238-46.

- fast, convenient online submission

- thorough peer review by experienced researchers in your field

- rapid publication on acceptance

- support for research data, including large and complex data types

- gold Open Access which fosters wider collaboration and increased citations

- maximum visibility for your research: over $100 \mathrm{M}$ website views per year 